\title{
Indoor height determination of the new absolute gravimetric station of L'Aquila
}

\author{
Marco Fortunato $^{1}$, Augusto Mazzoni ${ }^{1}$, Alberico Sonnessa ${ }^{2}$, Giovanna Berrino ${ }^{3}$, \\ Filippo Greco ${ }^{4}$, Federica Riguzzi*,5 \\ (1) DICEA, Sapienza Università, Roma, Italy \\ (2) DICATECh Politecnico di Bari, Bari, Italy \\ (3) Istituto Nazionale di Geofisica e Vulcanologia, Sezione di Napoli, Osservatorio Vesuviano, Italy \\ (4) Istituto Nazionale di Geofisica e Vulcanologia, Sezione di Catania, Osservatorio Etneo, Italy \\ (5) Istituto Nazionale di Geofisica e Vulcanologia, Sezione di Roma, Osservatorio Nazionale dei Terremoti, Italy
}

Article history: received April 22, 2020; accepted July 19, 2020

\section{Abstract}

\begin{abstract}
In this paper we describe all the field operations and the robust post-processing procedures to determine the height of the new absolute gravimetric station purposely selected to belong to a new absolute gravimetric network and located in the Science Faculty of the L'Aquila University (Italy). This site has been realized indoor in the Geomagnetism laboratory, so that the height cannot be measured directly, but linking it to the GNSS antenna of AQUI benchmark located on the roof of the same building, by a classical topographic survey.

After the topographic survey, the estimated height difference between AQUI and the absolute gravimetric site AQUIg is $14.970 \pm 0.003 \mathrm{~m}$. At the epoch of the 2018 gravimetric measurements, the height of AQUI GNSS station was $712.974 \pm 0.003 \mathrm{~m}$, therefore the estimated ellipsoidal height of the gravimetric site at the epoch of gravity measurements is $698.004 \pm 0.005 \mathrm{~m}$. Absolute gravity measurements are referred to the equipotential surface of gravity field, so that the knowledge of the geoidal undulation at AQUIg allows us to infer the orthometric height as $649.32 \mathrm{~m}$.
\end{abstract}

Keywords: Classical topographic survey; GNSS; Absolute gravity measurements; L’Aquila; Indoor measurements.

\section{Introduction}

Gravity changes measured on the Earth's surface consist of two terms: the effect of ground vertical displacement and internal mass redistribution. Gravity observations alone cannot differentiate between the two contributions. Therefore, the simultaneous measurement of gravity and vertical deformation over time helps to separate the competing effects of ground deformation and mass-fluid redistribution.

In the last years, there has been a worldwide development of GNSS networks useful to detect tectonic deformations [e.g. Kreemer et al., 2014]. On the contrary, the high costs of terrestrial gravimeters have limited their use [Carbone et al., 2017]. 


\section{Marco Fortunato et al.}

Gravity and physical heights are strictly connected throughout the gravity potential of the Earth's gravity field. Absolute gravity stations provide accurate starting values for gravity surveys, and GNSS constellation allows to estimate the precise point positioning on the Earth's surface.

The technical development of new kind of absolute gravimeters has increased the accuracy of the gravity measurements to the $\mu \mathrm{Gal}$ level, and the development of several permanent GNSS networks has significantly improved the determination of coordinates of points located on the Earth's surface.

Consequently, it is possible now to study geophysical processes with finer accuracy and their time evolution. However, there are numerous situations where satellite systems must be merged with traditional terrestrial surveying techniques. These include some interesting experiments of fundamental physics, in which the coordinates of particle detectors located in underground tunnels had to be estimated. In particular, the coordinates of the starting point of emission located at CERN (Geneva) and the target detector device located at Laboratori Nazionali del Gran Sasso (LNGS, Assergi, L'Aquila) were estimated linking outdoor GNSS with indoor benchmarks through classical topographic surveys [Crespi et al., 1999; Colosimo et al., 2012].

Similar situation is the case of underground or indoor gravimetric surveys, where the height of the gravimetric reference point should be determined precisely starting from an outdoor reference point with known coordinates. In this case, the use of classical observation techniques and instruments (e.g. total stations, levels), is crucial to measure the height difference between a GNSS reference station and a gravimetric benchmark. Furthermore, precise coordinates are necessary especially when a gravimetric station is also identified as a node of a gravimetric / altimetric reference network.

The Italian area is affected by ongoing deformations and/or mass transfer of different origin acting on very different temporal scales that modify significantly the gravity field over time.

In geodynamic areas, the main contributions to gravity changes are induced by episodic events due to volcanoes and earthquakes that individually can affect the gravity field, generally within few to hundreds of $\mu \mathrm{Gal}$ [e.g. Riguzzi and Doglioni, 2020]. However, since these events often repeat over time, their effects can cumulate significantly.

In 2018 INGV funded a project aimed to detect gravity variations and ground deformations over different timescale possibly associated with the post-seismic relaxation affecting the area where the recent seismic events of LAquila (2009 Mw 6.3 - inset in Figure 1 top-right) and Amatrice-Norcia (2016 Mw 6.1 and 6.5) took place. The impact of such events on the local gravity field has been recently modeled showing that the maximum gravity change reached about $170 \mu \mathrm{Gal}$ [Riguzzi et al., 2019]. Furthermore, the medium-long-term gravity and ground deformation variations related to post-seismic relaxation are expected as consequence of vertical deformation of the Earth surface and/or of the internal boundaries separating layers at depth with different densities.

Another interesting geophysical process active in the L'Aquila area is the deformation induced by ground water level changes in the aquifers: the filtered time series of long-term deformations correlate well with the time series of rainfall excess and gravity field variations in term of equivalent water height (EWH) from GRACE data [Riguzzi et al., 2020].

Therefore, a multidisciplinary approach carrying out joint measurements of deformation and gravity, is fundamental to understand the role of such concurrent geophysical process.

To this aim a network of five absolute gravity and GNSS stations was realized in Central Italy (Terni, Popoli, Sant'Angelo Romano, L'Aquila University and LNGS (Offices Building [Berrino et al. 2018]). The repetition of absolute gravity and GNSS measurements over time could provide valuable information about the deep processes related to earthquakes and hydrology, over a critical seismogenetic area, where catastrophic events occurred in the last decades.

In the next sections, we will focus on the site of L'Aquila University where a permanent GNSS station (AQUI), managed by the Italian Space Agency and contributing to the EUREF network, is continuously operating on the roof of the Science Faculty (Coppito, L'Aquila). In the basement of the same building we realized the absolute gravimetric station (AQUIg), indoor the Geomagnetism laboratory of the Physics Department. It has also been selected among the stations that will belong to the new "first order" Italian gravimetric/altimetric reference network which is in planning. Furthermore, the high precision of the absolute gravity value will also impact on relative gravity measurements performed for other purposes in the area (e.g. hydrogeology) that could be referred and tested to this new absolute gravity point.

First, we will give a description of AQUI and the methodology followed to obtain the precise coordinates referred to the Antenna Reference Point (ARP, Figure 1); then we will describe AQUIg and the absolute gravity measurements; in the end, we will describe the classical topographic survey to estimate the height difference between the ARP of AQUI and the gravimetric benchmark AQUIg located four floors below the roof of the same building. 

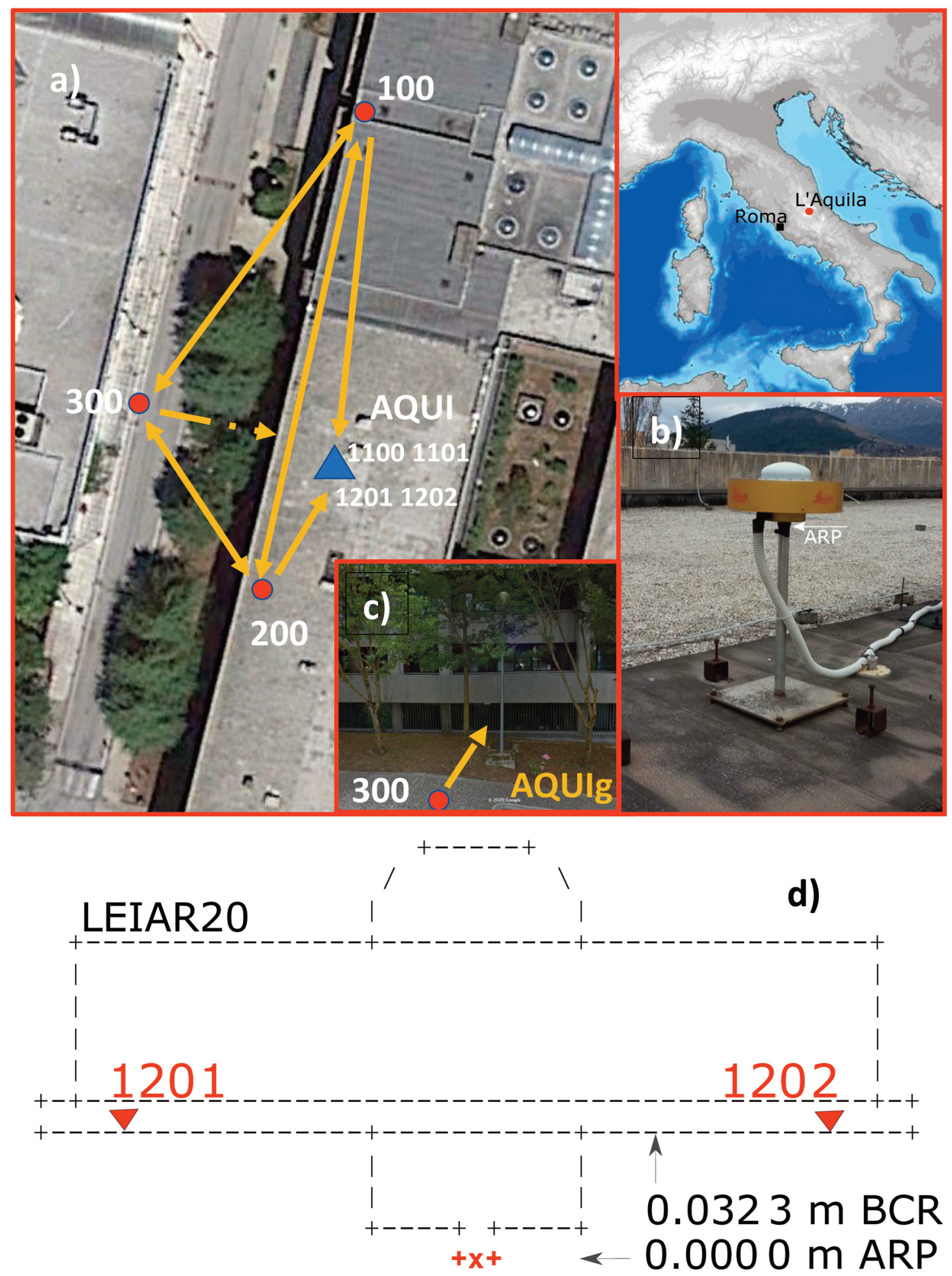

Figure 1. a) Google Earth view of the Faculty facility with AQUI (triangle) and the classical topographic network: with orange lines the connections between the surveyed points (white numbers). b) AQUI GNSS antenna LEIAR20, the white arrow indicates the Antenna Reference Point (ARP) with respect to which the ellipsoidal height of AQUI is defined. c) The window of Geomagnetism laboratory in the basement where AQUIg (400) is located, as seen from station 300.d) sketch of AQUI antenna showing the target point of measure (1201 and 1202) at the BCR level and the useful dimensions. 


\section{Marco Fortunato et al.}

\section{Site description and coordinates estimation of AQUI}

The permanent GNSS station of AQUI was installed in 1999 and currently maintained by the Italian Space Agency at the Science Faculty of the L'Aquila University, located in Coppito (Figure 1a). The antenna, a LEIAR20 chokering, is settled on the roof-top terrace of the building and screwed on a steel pillar (Figure 1b). The reference height is measured at the ARP, that is at the bottom of the antenna screw (Figure 1d).

Data collected at this station are included within the long-term routine analysis performed at INGV by the Bernese software [Beutler et al., 2007] to estimate the coordinate time series (Up, East and North) of a large network of more than 1000 continuous GNSS stations located in the Italian peninsula and surrounding areas [Devoti et al., 2017]. The satellite orbits and the Earth's orientation parameters are fixed to the combined IGS products and an $a$ priori loose constraint of $10 \mathrm{~m}$ is assigned to all site coordinates. The elevation-dependent phase center corrections and absolute phase center calibrations are applied. The troposphere modelling consists of an a priori dry-Niell model corrected by the estimation of zenith delays at 1-hour intervals and one horizontal gradient parameter per day, at each site using the wet-Niell mapping function. The effect of ionosphere is modelled applying the ionosphere-free linear combination of L1 and L2. The ambiguity resolution is based on the Quasi Ionosphere Free (QIF) baseline-wise analysis. The final network solution is solved with back-substituted ambiguities, if integer; otherwise ambiguities are considered as real valued measurement biases. The daily solutions are estimated in a loosely constrained reference frame; therefore, the coordinates result randomly translated or rotated from day-today and their covariance matrix components are large (order of meters). To express the coordinate time series in a unique reference frame and to compute the real covariance matrix, we perform two main transformations. First the loose covariance matrix is projected into a well-defined reference frame imposing tight internal constraints (at millimeter level), and then coordinates are transformed into the IGS14 [Altamimi et al., 2016] by a 4-parameter Helmert transformation (translations and scale factor) based on 45 sites located in central Europe, the core stations for the regional reference frame realization.

The site velocities are estimated by fitting simultaneously a linear drift, eventual episodic offsets due to phenomena of different nature (e.g. instrumental changes, earthquake occurrence) and annual sinusoids to all the coordinate time series (Figure 2). The formal velocity errors obtained after the inversion are re-scaled by a posterior global variance factor, to account for the noise of the data and possible residual modelling errors.
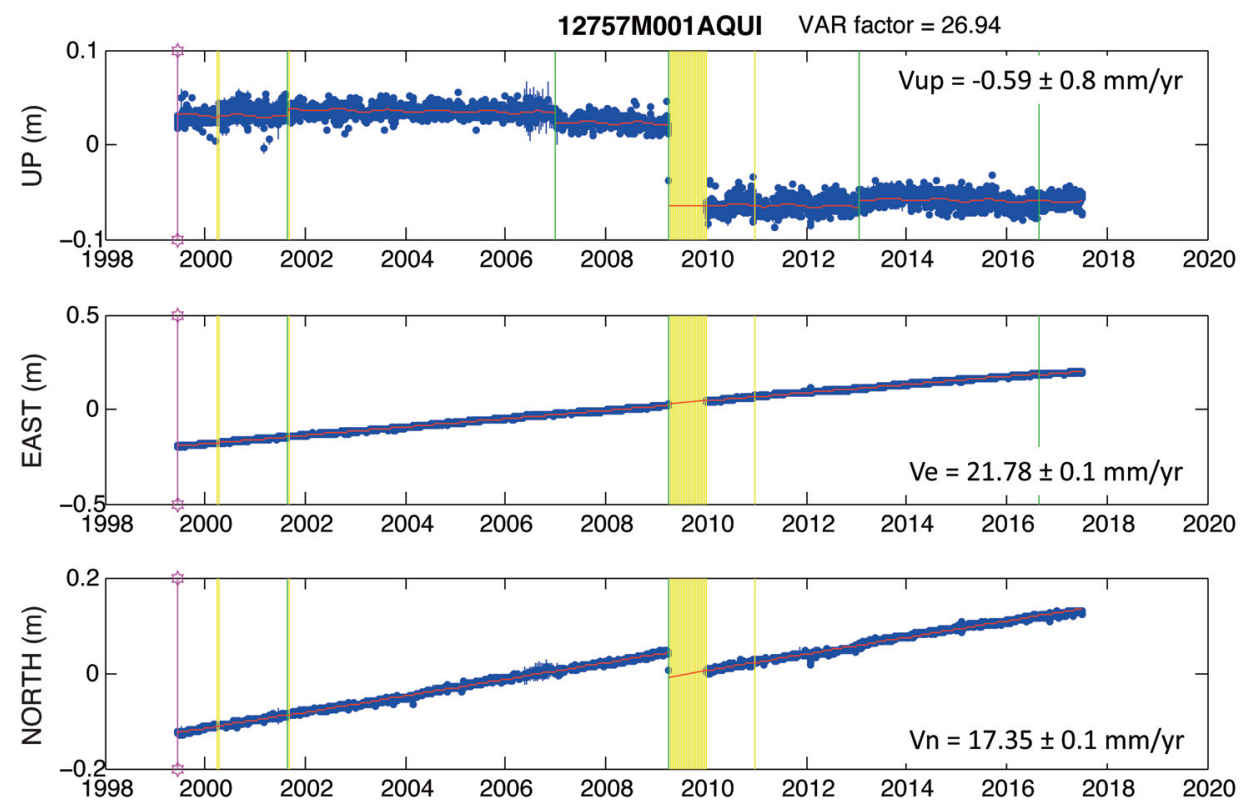

Figure 2. AQUI time series of coordinates (Up, East and North). The green lines indicate the epochs of instrumental step estimation and removal from the linear interpolation (due to episodic instrumental changes, or earthquakes); the yellow lines indicate the outliers detected by processing. 
The linear components, which represent the long-term tectonics, are useful to propagate the coordinates of the stations at a given epoch by simply applying the classical linear motion equation

$$
x^{i}\left(t_{k}\right)=x_{0}^{i}+v^{i} \cdot t_{k}
$$

where $\mathrm{x}^{\mathrm{i}}\left(\mathrm{t}_{\mathrm{k}}\right)$ is the position of the $\mathrm{i}$-th station at epoch $\mathrm{t}_{\mathrm{k}}, \mathrm{x}_{0}^{\mathrm{i}}$ is the initial position and $\mathrm{v}_{\mathrm{x}}^{\mathrm{i}}$ is the velocity component of i-th station.

After processing, the vertical velocity estimate of AQUI is $-0.6 \pm 0.8 \mathrm{~mm} / \mathrm{yr}$. It can be used to propagate the height to the epoch of gravimetric measurements applying (1). The ellipsoidal height of AQUI provided by EUREF in IGS14 reference frame at epoch 210/2018 (corresponding to July 29) is $712.974 \pm 0.003 \mathrm{~m}$. The first DOY of our measurements was 164 and the last 277 (June 12 - October 4, Table 1); therefore, the IGS14 height release is near the middle of our time span. Considering that the AQUI height decreases at a rate of $-0.6 \pm 0.8 \mathrm{~mm} / \mathrm{yr}$, we can neglect the variation of IGS14 height during the time of our measurements.

\section{Absolute gravity measurements and results}

The absolute gravity measurements were carried out at the same building hosting the GNSS station on the floor of the Geomagnetism laboratory, and approximately along the same vertical. A schematic monograph of the gravimetric station AQUIg is shown in Figure 3. The gravity measurements were performed with two absolute gravimeters available at INGV: the transportable Micro-g LaCoste FG5\#238 (managed by INGV-OE; Figure 3d) and the portable Micro-g LaCoste A10\#39 (managed by INGV-OV; Figure 3e). The FG5 gravimeter is designed for measurements in laboratory or like-laboratory sites; it is not well-suited for portable use on the field since it requires more logistics and precautions, but it is feasible. There are many examples of operators using them in the field. [e.g. Kazama and Okubo, 2009; Greco et al., 2012; 2015; Kazama et al., 2015; Carbone et al., 2017]. On the other hand, the $\mathrm{A} 10$ is designed on purpose for field measurements (indoor and outdoor) and fast field operations, while preserving the characteristics of a laboratory instrument. Both instruments work using a ballistic free-fall method. A test mass (retro-reflective corner cube) is dropped vertically by a mechanical device (drug-free cart) inside a vacuum dropping chamber; the vacuum is maintained by an ion pump that runs continuously. The absolute $g$ value is measured through the reconstructed trajectory of the dropping mass subjected to the gravity field. A laser interferometer generates optical interference fringes as the test mass falls. The fringes are counted and timed with an atomic clock to obtain precise time and distance pairs. These data are fitted to a parabolic trajectory to give a measured value of $g$ [Niebauer et al., 1995]. A dedicated software provides the automatic data acquisition, the real time processing and the automatic data storage. It also automatically corrects the measured $g$ value for gravity changes due to solid-earth tides, ocean tide loadings, polar motion and local air pressure changes. It also permits to reprocess data, and if necessary, to reduce automatically the $g$ values from the measured heights at any convenient height from the ground, through the measured local value of the vertical gravity gradient. The instrumental accuracy of the FG5 is about $1-2 \mu \mathrm{Gal}$ as reported by the manufacturer [Niebauer et al., 1995]; the precision is timedependent, and it is given by the drop-drop scatter (single-drop scatter) divided by the square-root of the number of drops. A precision of $1 \mu \mathrm{Gal}$ or better can be achieved within an hour at most sites, if the FG5 is running continuously.

Regarding the A10, in laboratory conditions, it can be used like an FG5; during field surveys, to obtain reliable values of $g$, it needs session length from 0.5 to $1.5 \mathrm{~h}$. The precision is $10 \mu \mathrm{Gal}$ in $10 \mathrm{~min}$ and the repeatability is within $10 \mu \mathrm{Gal}$. Although the accuracy and precision of the A10 is less than that of the FG5, there are some characteristics, such as portability and ease of operation in outdoor applications, which make it a desirable instrument in absolute gravimetric field surveys.

Both FG5\#238 [Greco et al., 2012; 2015] and A10\#39 have been inter-compared with the absolute gravimeter IMGC-02 (realized by the Istituto Nazionale di Ricerca Metrologica, INRiM [D’Agostino et al., 2008]) that has been officially recognized as the Italian National Primary Standard [D’Agostino et al. 2007]. The FG5\#238 also participated to the periodical CIPM-Key Comparisons [Jiang et al., 2012; Newell et al., 2017; Pálinkáš et al., 2017]. 


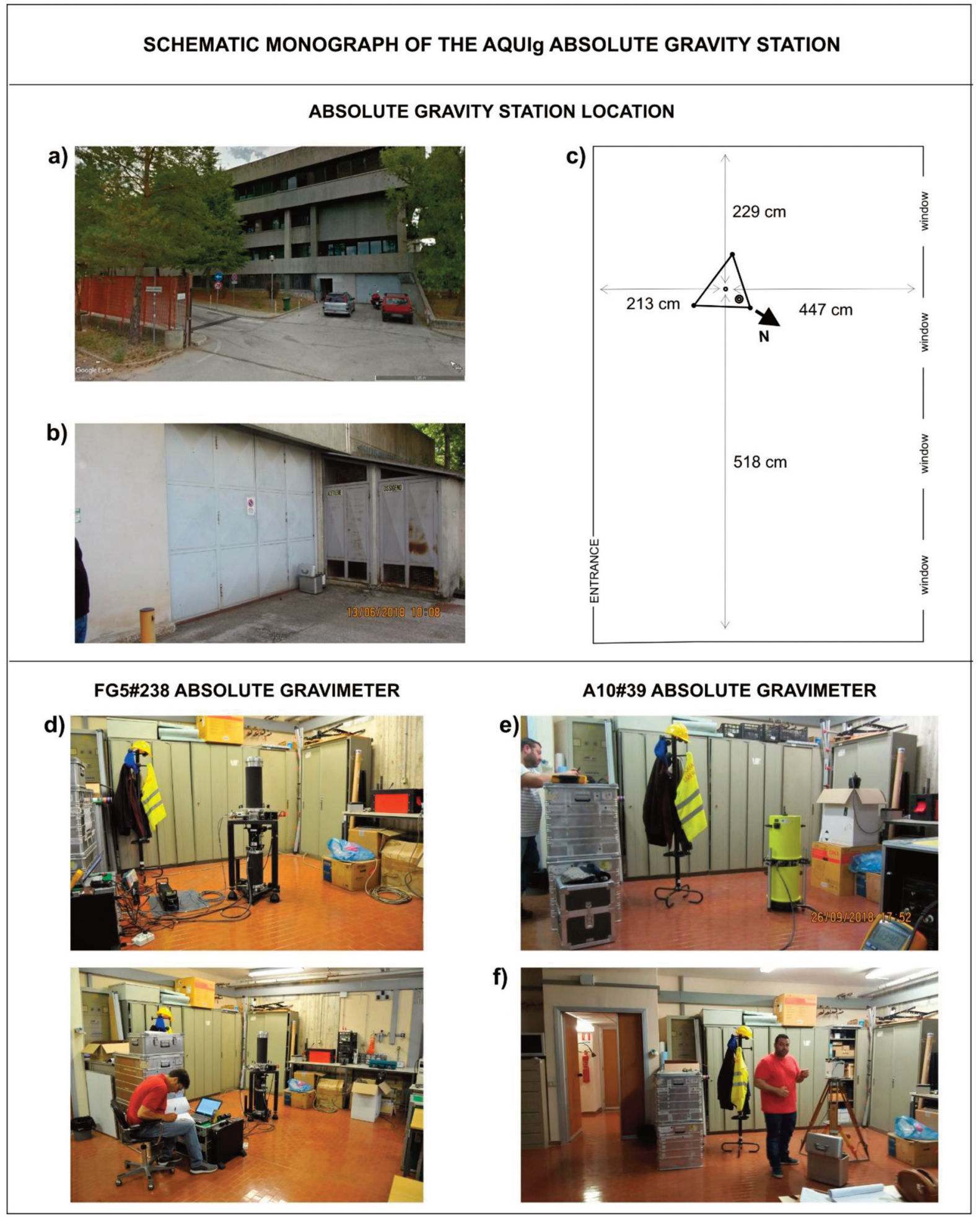

Figure 3. Schematic monograph and pictures of the absolute gravity station AQUIg. a) and b) External view of the building and the location of the satellite station, used for fast link with the absolute point, with the exact position of the relative gravimeter LCR-D85. c) Map of the Geomagnetism laboratory of the University of L'Aquila, with the exact location of the measurement point. d) and e) The Micro-g LaCoste FG5\#238 and A10\#39 during the measurement sessions, respectively. f) The supports to measure the vertical gravity gradient.

Due to different instrument design of the FG5\#238 and the A10\#39, their measured $g$-values refer to different heights from the ground. The FG5\#238 refers to a measurable variable height of about $1.3 \mathrm{~m}$; the A10\#39 refers to 
a constant height of $0.72 \mathrm{~m}$. Therefore, to compare the $\mathrm{g}$ values collected by the two instruments, we referred all the measurements to a common height of $0.72 \mathrm{~m}$, corresponding to the A10\#39 reference height, and to the ground using the vertical gravity gradient measured in June 2018 at the same absolute station with a LaCoste \& Romberg model D SN\#85 relative gravimeter ([Berrino et al., 2018]; Table 1, Figure 3f). At the same time, to realize excenter ties, also a satellite gravimetric station has been set up outside the building (Figure 3a-b); here the absolute value of $g$ has been reported through relative measurements from the nearby absolute-indoor site.

The new station AQUIg was measured twice with the FG5\#238, in June and October 2018 and during the second half of September 2018 with the A10\#39. The instruments were placed directly on the floor, which guaranteed stability during the measurements. Figures $3 \mathrm{~d}$ and $3 e$ show the instruments placed in the AQUIg site. With the A10\#39, a long-field (1 hour) and a long-laboratory (14 hours during the night) measurements were carried out on 26 and 27 September 2018. The environmental parameters during the measurement session were enough stable. We had a small problem only during the end of the long session of A10 measurements due to the onset of strong wind during the night, which caused in the final phase a drift in the distribution of the sets and then unreliable values. Therefore, data have been recalculated eliminating the sets deemed unreliable. The final $g$ values and the associated combined uncertainty, are reported in Table 1.

Table 1: Absolute gravity measurements at AQUIg

\begin{tabular}{|c|c|c|c|c|c|}
\hline $\begin{array}{c}\text { Date } \\
\text { Time UTC } \\
\text { (from } \div \text { to) }\end{array}$ & $\begin{array}{c}\text { Height } \\
\text { of measure } \\
(\mathrm{m})\end{array}$ & $\begin{array}{c}\text { Number of } \\
\text { sets/drops per } \\
\text { set/total drops }\end{array}$ & $\begin{array}{c}g \text { at measure } \\
\text { height } \\
\pm \text { Combined } \\
\text { Uncertainty } \\
(\mu \mathrm{Gal})\end{array}$ & $\begin{array}{c}\text { g at } 0.72 \text { m } \\
\pm \text { Combined } \\
\text { Uncertainty } \\
(\mu \mathrm{Gal})\end{array}$ & $\begin{array}{l}g \text { at ground } \\
\pm \text { Combined } \\
\text { Uncertainty } \\
(\mu \mathrm{Gal})\end{array}$ \\
\hline $\begin{array}{c}\text { 13-14 June } \\
201813: 54 \div 05: 54\end{array}$ & $\begin{array}{c}\text { FG5\#238 } \\
1.2932\end{array}$ & $15 / 100 / 1500$ & $980203143.5 \pm 3.4$ & $980203298.0 \pm 3.5$ & $980203492.1 \pm 4.0$ \\
\hline $\begin{array}{c}\text { 26 Sept. } \\
201815: 43 \div 16: 40\end{array}$ & A10\#39 0.72 & $20 / 120 / 2400$ & $980203279.2 \pm 4.1$ & $980203279.2 \pm 4.1$ & $980203473.3 \pm 4.3$ \\
\hline $\begin{array}{c}\text { 26-27 Sept. } \\
\text { 201817:01 } \div 06: 04\end{array}$ & A10\#39 0.72 & $18 / 120 / 2069$ & $980203271.9 \pm 3.9$ & $980203271.9 \pm 3.9$ & $980203466.0 \pm 4.1$ \\
\hline $\begin{array}{c}\text { 03-04 Oct. } \\
\text { 201814:46 } \div 05: 46\end{array}$ & $\begin{array}{c}\text { FG5\#238 } \\
1.2952\end{array}$ & $16 / 100 / 1600$ & $980203140.2 \pm 3.4$ & $980203295.3 \pm 3.5$ & $980203489.4 \pm 4.0$ \\
\hline
\end{tabular}

Vertical gravity gradient (12 June 2018) $\mathrm{dg} / \mathrm{dh}=-269.6 \pm 1.7 \mu \mathrm{Gal} / \mathrm{m}$

Relative measurement from indoor absolute station to outdoor relative station

(12 June 2018 using LCR-D85) $\Delta \mathrm{g}=+90 \pm 5.0 \mu \mathrm{Gal}$

Table 1. Absolute gravity measurements collected at the Geomagnetism laboratory of the University of L'Aquila (AQUIg) during June-October 2018 period by FG5\#238 and A10\#39 absolute ballistic gravimeters. The columns in the table show: (a) Data and measurement time interval in UTC; (b) the used instrument and the measured height $h$ (elevation above the ground to which $g$ is measured); (c) the number of sets, drop per sets and total number of drops for each session; d) absolute gravity values at the measured height h; (e) absolute gravity values at the reference height of $0.72 \mathrm{~m}$; (f) absolute gravity values on the ground. For each absolute gravity value is also indicated the combined standard uncertainty of $g$, which takes into account the contributions due to the instrument uncertainty, the site-dependent uncertainty, the statistical uncertainty due to the scattering and the uncertainty of the vertical gravity gradient. In the lines below the value of the locally measured free-air vertical gradient $\gamma$ with the uncertainty and the gravity difference (in $\mu \mathrm{Gal}$ ) measured from AQUIg station and the external satellite station are also reported. 


\section{Marco Fortunato et al.}

The combined uncertainty is given by:

$$
\delta_{\text {tot }}=\sqrt{ }\left(\Sigma_{\text {sys }}^{2}+\delta_{\text {stat }}^{2}\right)
$$

where $\delta_{\text {stat }}$ is the statistical uncertainty given by the set scatter (standard deviation) divided by the square root of the number of sets:

$$
\delta_{\text {stat }}=\sigma_{\text {set }} / \sqrt{\mathrm{N}_{\text {set }}}
$$

and $\Sigma_{\text {sys }}$ is the systematic uncertainty corresponding with the sum of the estimated uncertainties for many different components of the measurement, due to: a) modelling of geophysical processes (i.e. Barometric, Polar Motion, Earth Tide, Ocean Loading); b) system (Laser, Clock and System Model); c) environmental (is highly site dependent); d) set-up (is depending on both the instrument and the operator) and e) gradient (if applied). For both instruments, as systematic uncertainty we considered $3.34 \mu \mathrm{Gal}$ such as the best representative value of the sum of all these contributions.

Measurements collected with the FG5\#238 in June and October 2018 exhibited a small gravity decrease of -2.7 $\mu \mathrm{Gal}$ (Figure 4). This result indicates that the agreement between the two measurements is fairly good because the detected difference is compatible with the measurements uncertainties. The results of the measurements collected with the A10\#39 show a difference of $-7.3 \mu \mathrm{Gal}$ when the instrument was used with different set-up (long-field and long-laboratory measurements). However, both measurements are in good agreement, considering that the declared instrumental repeatability for this type of instrument is $\pm 10 \mu \mathrm{Gal}$.

Finally, by comparing the values obtained with both instruments, referred to the same elevations $0.72 \mathrm{~m}$ (from the ground) and to the ground (with height measurement explained in the next section), we found a mean discrepancy of $-19.7 \mu \mathrm{Gal}$ between A10\#39 and FG5\#238 values (Figure 4). To transfer the FG5\#238 value to the A10 height of measure and the values acquired with the two instruments to the ground, we use the vertical gravity gradient locally measured, considering its error (Table I) to calculate the final error on reduced $g$ values.

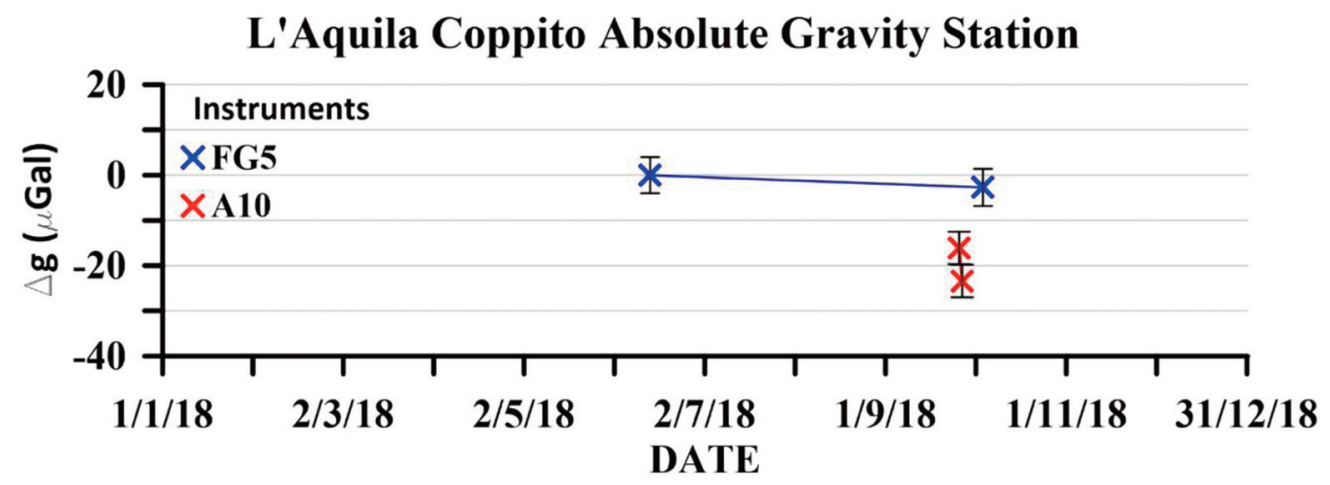

Figure 4. Comparison between the absolute gravity values measured with the FG5\#238 and the A10\#39 absolute gravimeters in the time interval June-October 2018, after reduction to the ground, that is the AQUIg quoted point (Table 5), using the experimental vertical gravity gradient measured at the same station.

\section{Topographic survey and estimation of the height difference between AQUI and AQUlg}

The height difference between AQUI and AQUIg was estimated through a classical topographic survey carried out on April 5, 2019 with one Total Station (STONEX R2-2 plus), four tripods and three reflector prisms (Figure 5). 
In order to link the roof to the basement, three station points were used to realize a redundant network (Figure 1a, 1c). Two stations points were realized on the roof of the building (100 and 200), ensuring mutual visibility and a different point of view of the AQUI antenna located on the same level. In addition, these two station points were realized in order to observe and be observed by the third station point (300) realized at ground level outside the building (Figure 1a, 1c). Finally, from the third station point (300) it was possible to observe a prism installed on the AQUIg point placed indoor (400). The height difference between the prism and the AQUIg point has been directly measured with an aluminum graduated rod.

As previously mentioned, the AQUI height is referred to the ARP of the antenna. The ARP, being a monodimensional reference for the height, is not directly measurable as a three-dimensional point. Therefore, in order to attach the survey network to the ARP, the following procedure has been applied.

A physical antenna plane has been chosen in order to be directly collimated, minimizing the collimation errors, from the two station points on the roof. In particular 2 points (1201 and 1202) belonging to the BCR plane (Figure 1d, antenna) were observed from station 200 in order to attach the ARP and other two auxiliary points (1100 and 1101) were observed from station 100 in order to improve the reliability of the heights. One mono-dimensional stochastic $(0.5 \mathrm{~mm} \mathrm{rms})$ constrain equation has been used in order to set at the same height the two points belonging to BCR plane of the antenna and another has been added to constrain the heights of the other two points. The observations used in the final adjustment are shown in Table 2.

Table 2: Measured angles and distances

\begin{tabular}{|c|c|c|c|c|c|c|c|}
\hline Number & Point & Point & $\begin{array}{l}\text { Hor. Dir } \\
\text { (grad) }\end{array}$ & Distance (m) & $\begin{array}{l}\text { Zen. Angle } \\
\text { (grad) }\end{array}$ & Inst. $\mathrm{H}(\mathrm{m})$ & Target H (m) \\
\hline 1 & 200 & 100 & 382.0908 & 38.968 & 99.6600 & 0 & 0 \\
\hline 2 & 200 & 100 & 382.1029 & 38.967 & 99.6624 & 0 & 0 \\
\hline 3 & 200 & 300 & 334.4915 & & 129.4003 & 0 & 0 \\
\hline 4 & 200 & 300 & 334.5070 & & 129.4028 & 0 & 0 \\
\hline 5 & 200 & 1201 & 72.5445 & 6.330 & 109.9976 & 0 & 0.032 \\
\hline 6 & 200 & 1201 & 72.5490 & 6.341 & 110.0030 & 0 & 0.032 \\
\hline 7 & 200 & 1202 & 75.6723 & 6.293 & 110.0836 & 0 & 0.032 \\
\hline 8 & 200 & 1202 & 75.6655 & 6.292 & 110.092 & 0 & 0.032 \\
\hline 9 & 100 & 300 & 106.5884 & & 125.8688 & 0 & 0 \\
\hline 10 & 100 & 300 & 106.5933 & & 125.8706 & 0 & 0 \\
\hline 11 & 100 & 200 & 67.4128 & 38.965 & 100.3350 & 0 & 0 \\
\hline 12 & 100 & 200 & 67.4155 & 38.965 & 100.3283 & 0 & 0 \\
\hline 13 & 100 & 1100 & 56.8776 & 38.746 & 101.9689 & 0 & 0 \\
\hline 14 & 100 & 1100 & 56.8766 & 38.746 & 101.9730 & 0 & 0 \\
\hline 15 & 100 & 1101 & 57.1510 & 38.554 & 101.9788 & 0 & 0 \\
\hline 16 & 100 & 1101 & 57.1520 & 38.549 & 101.9786 & 0 & 0 \\
\hline 17 & 300 & 200 & 121.5770 & & 70.5600 & 0 & 0 \\
\hline 18 & 300 & 200 & 121.5790 & & 70.5601 & 0 & 0 \\
\hline 19 & 300 & 200 & 121.5924 & & 70.5621 & 0 & 0 \\
\hline 20 & 300 & 400 & 74.3766 & 21.154 & 108.5646 & 0 & 1.698 \\
\hline 21 & 300 & 400 & 74.3782 & 21.154 & 108.5667 & 0 & 1.698 \\
\hline 22 & 300 & 100 & 8.3384 & & 74.0935 & 0 & 0 \\
\hline 23 & 300 & 100 & 8.3530 & & 74.0917 & 0 & 0 \\
\hline
\end{tabular}

Table 2. Topographic measurements, from left to right columns: measure number, start- point of measure, end- point of measure, horizontal angle between points, distance, zenithal angle, instrumental height, fixed height of targets. 


\section{Marco Fortunato et al.}

The network has been adjusted using the scientific package CALGE [Forlani, 1990]. A minimum constrain approach has been performed fixing the origin for the horizontal components of a local reference frame [Crespi et al., 2015] in station point 200 with the $x$ axis toward point 100 and fixing the up component in point 1201 to the ARP reference ellipsoidal height estimated as explained in Section 2. The adjustment has been carried out through few iterations starting from approximate values of the unknown parameters (i.e. point coordinates and station orientations). A priori values of observations weights have been defined on the basis of instrumental characteristics. After, as commonly performed in such scientific analysis [Crespi and Pinto, 1991], the weights have been iteratively refined in order to optimize the adjustment. Some zenith directions were discarded from the estimation due to their low reliability.

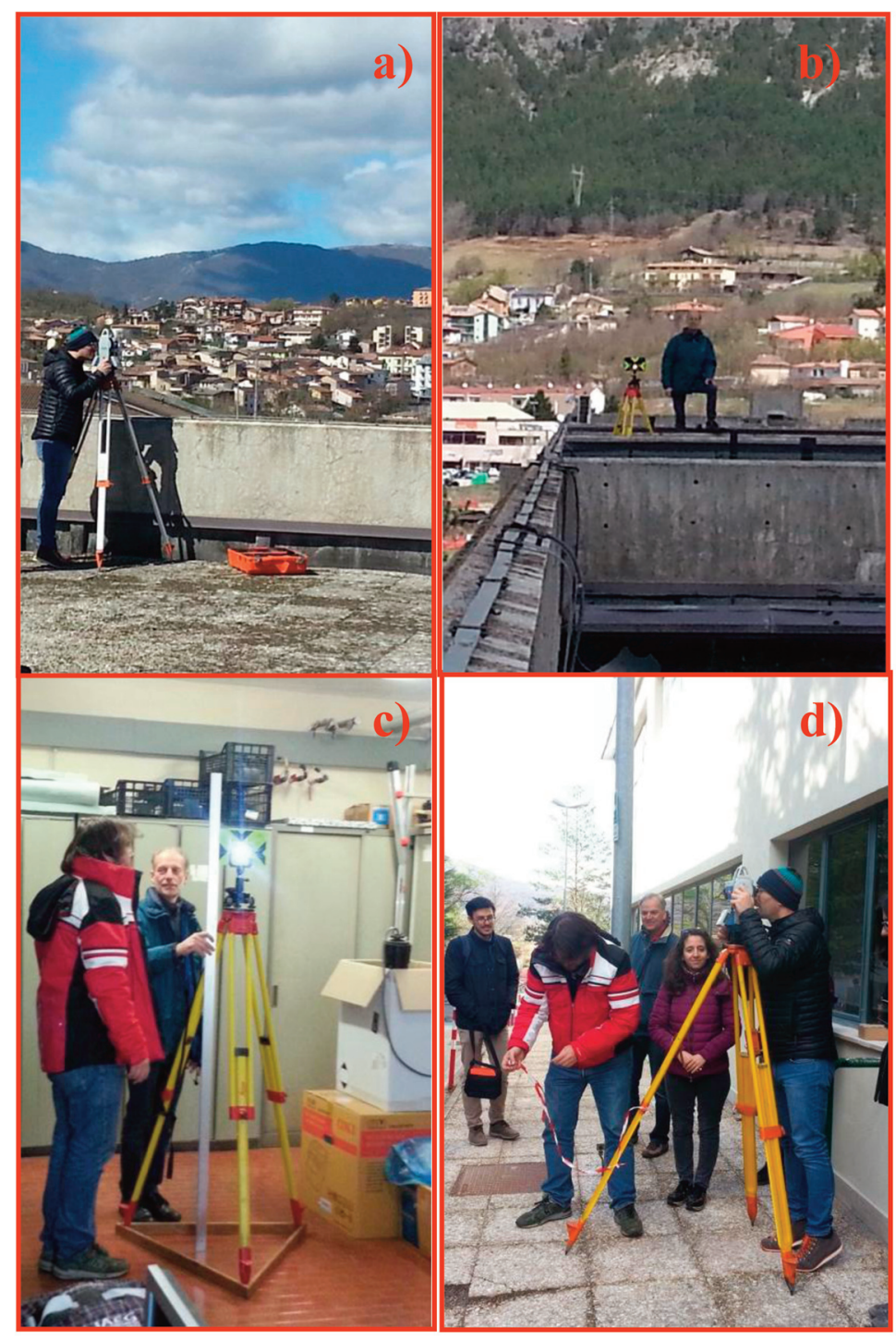

Figure 5. Images of the topographic survey: on the roof of the building, the total station (a) and the prism b) targeted from a); indoor the laboratory, the prism on tripod (c) targeted by the total station (d) located outside the laboratory. 


\section{Discussion and conclusions}

In this paper we describe how we determined the height of the absolute gravimetric station of L'Aquila, AQUIg, located indoor the Geomagnetism laboratory of L'Aquila University. We used two ballistic absolute gravimeters to gather the $g$ value at this station at the instrumental heights and then reporting the measurements to the AQUIg point which height has been estimated by the topographic survey (i.e. to the ground; Table 1), taking into account the measured vertical gradient of gravity. Table 1 reports all the results.

As for the height determination of AQUIg, since it cannot be measured directly by GNSS, it was estimated by a classical topographic survey. The aim was to determine the height difference between the GNSS antenna of AQUI benchmark and the indoor reference point of AQUIg. The topographic measurements consist of angles and distances in a local reference frame, as reported in Table 2. The adjustment characteristics and the statistic of the topographic survey are shown in Table 3; the estimated local coordinates are finally shown in Table 4.

Table 3: Adjustment features

\begin{tabular}{lc}
\multicolumn{2}{c}{ Table 3: Adjustment features } \\
Observations & 23 \\
\hline - horizontal directions & 23 \\
\hline - zenith angles & 14 \\
\hline - distances & 24 \\
\hline Parameters & 3 \\
\hline - coordinates & 3 \\
\hline - station orientation & 1 \\
\hline Constrained coordinates & 2 \\
\hline Constrained orientation & 39 \\
\hline Constrain equations & $10^{c c}$ \\
\hline Redundancy & $11.9^{c c}$ \\
\hline Prior variance of unit weight & $55.2,59.9$ \\
\hline Posterior variance of unit weight & $\chi^{2}$ test: ${ }^{2}$ sp
\end{tabular}

Table 3. Features of the topographic measurement adjustment; the input data (23 horizontal directions, 23 zenith angles, 14 distances), the unknowns (24 coordinates, 3 station orientations), the constraints and statistics of results.

\begin{tabular}{ccccccc}
\multicolumn{7}{c}{ Table 4: Adjusted coordinates and rms } \\
Point & $\mathrm{x}(\mathrm{m})$ & $\mathrm{rms}(\mathrm{x})(\mathrm{mm})$ & $\mathrm{y}(\mathrm{m})$ & $\mathrm{rms}(\mathrm{y})(\mathrm{mm})$ & $\mathrm{z}(\mathrm{m})$ & $\mathrm{rms}(\mathrm{z})(\mathrm{mm})$ \\
\hline 200 & 0.000 & 0 & 0.000 & 0 & 713.998 & 1 \\
\hline 100 & 38.966 & 3 & 0.000 & 0 & 714.202 & 2 \\
\hline 300 & 16.854 & 3 & 15.628 & 2 & 702.541 & 2 \\
\hline 1201 & 0.900 & 1 & -6.258 & 4 & 712.974 & 0 \\
\hline 1202 & 0.606 & 1 & -6.214 & 4 & 712.973 & 1 \\
\hline $\mathbf{4 0 0}$ & 15.142 & 2 & -5.265 & 5 & $\mathbf{6 9 8 . 0 0 4}$ & 2
\end{tabular}

Table 4. Adjusted coordinates in the local reference frame and rms. The $x$ axis is directed from point 200 (the origin) toward point 100, the $y$ axis is perpendicular to $x$. The estimated ellipsoidal heights are in the column $z$. 


\section{Marco Fortunato et al.}

In particular, a height difference of $14.970 \pm 0.003 \mathrm{~m}$ between the ARP height of AQUI antenna and the reference point of AQUIg has been estimated. Considering also the uncertainties of the measured height difference between the observed prism and AQUIg point and of the actual horizontal monumentation of the BCR plane of the antenna, it is possible to quantify a global precision for $\mathrm{AQUIg}$ height determination around $0.5 \mathrm{~cm}$. Therefore, the estimated ellipsoidal height of the gravimetric reference point AQUIg is $698.004 \pm 0.005 \mathrm{~m}$ (Table 5). To achieve the orthometric heights, useful to refer the gravity measurements to the equipotential surface, it is necessary to know the value of the geoidal undulation in AQUIg. This value can be retrieved by the regional model of Italian geoid estimated by the International Geoid Service at Politecnico di Milano [Barzaghi et al., 2007] and released by the Istituto Geografico Militare Italiano. The gravimetric geoid, integrated with GPS/levelling data, has an overall precision of around $3 \mathrm{~cm}$ over the entire Italian area. The value of geoid undulation in AQUIg is $48.688 \mathrm{~m}$, so that the orthometric height of AQUIg is $649.316 \mathrm{~m}$ (Table 5).

\begin{tabular}{cccccc} 
Point & \multicolumn{5}{c}{ Table 5: Coordinates and rms } \\
& $\begin{array}{c}\text { Latitude } \\
(\mathrm{deg})\end{array}$ & $\begin{array}{c}\text { Longitude } \\
(\mathrm{deg})\end{array}$ & $\begin{array}{c}\text { Ellipsoidal Height } \\
(\mathrm{m})\end{array}$ & $\begin{array}{c}\text { Geoidal undulation } \\
(\mathrm{m})\end{array}$ & $\begin{array}{c}\text { Orthometric Height } \\
(\mathrm{m})\end{array}$ \\
\hline AQUI & 42.3682 & 13.3502 & $712.974 \pm 0.003$ & 48.688 & 664.286 \\
\hline AQUIg & 42.3682 & 13.3502 & $698.004 \pm 0.005$ & 48.688 & 649.316 \\
\hline
\end{tabular}

Table 5. Coordinates of AQUI and AQUIg at a mean epoch between the absolute gravimetric measurements. Latitude and longitude are the same within four decimals. Ellipsoidal heights, geoidal undulation and orthometric heights are also reported.

Finally, it is useful to remark that this work lays the foundation for a new strategy of multidisciplinary research of time dependent processes not only to monitor volcanoes [e.g. Berrino et al., 1994; Greco et al., 2012; Carbone et al., 2017] and subsiding areas [e.g. Zerbini et al., 2007], but also to study seismogenic areas.

Moreover, other geodetic applications will also benefit from the high precision absolute gravity data now available in this area (e.g. proper definition of a modern height system in Italy; improvements in the estimate of the geoid that is nowadays fundamental in converting ellipsoidal heights into normal or orthometric heights).

Acknowledgements. The Research has been developed within the Project "Ricerca Libera" 2018 entitled: "Feasibility of an absolute gravity network in central Italy: toward a multi-disciplinary approach to natural risk assessment", funded by INGV, D.P. 453 8/11/2017 (Prot. N. 14830 - Proponents: G.B, F.G. and F.R. - Responsible G.B.). We are grateful to Patrizia Francia,Andrea Piancatelli and Vinicio Argentieri to have made available the Geomagnetism laboratory and the roof-top terrace for the gravity and classical topographic surveys. We are also indebted with Mattia Crespi for the plan and supervision of the topographic survey; Lorenzo Lastilla, Michela and Roberta Ravanelli are also acknowledged for their help during the survey. G.B., F.G. and F.R. are in debt and sincerely thanks very much A. Amantia (absolute FG5\#238 measurements), A. Massucci (GNSS measurements) and G. Ricciardi (relative and absolute A10\#39 measurements) for their invaluable support in carrying out gravity and GNSS measurements during the course of the project. We wish to thank the Editor Fabio Caratori Tontini and two anonymous reviewers for the fruitful suggestions.

\section{References}

Altamimi, Z., P. Rebischung, L. Metivier, and X. Collilieux (2016). ITRF2014: A new release of the International Terrestrial Reference Frame modeling nonlinear station motions, J. Geophys. Res. Solid Earth, 121, doi:10.1002/2016JB013098

Barzaghi R., A. Borghi, D. Carrion, G. Sona (2007). Refining the estimate of the Italian quasi-geoid. Bollettino di Geodesia e Scienze Affini, 66 (3), 145-159. 
Berrino G. (1994) Gravity changes induced by height-mass variations at the Campi Flegrei caldera. J Volcanol. Geotherm. Res., 61:293-309. https://doi.org/10.1016/0377-0273(94)90010-8

Berrino G., Greco F., Riguzzi F., Amantia A., Massucci A., Ricciardi G. (2018). Indagini gravimetriche e GPS in Italia centrale per il controllo delle aree sismogenetiche. $37^{\circ}$ GNGTS National Meeting, Bologna, November 19-21, Poster Section. Extended Abstract, 170-172, in http://gngts.inogs.it/ and in Earth Prints Repository http://hdl.handle.net/2122/12057

Beutler G., H. Bock, R. Dach, P. Fridez, A. Gäde, U. Hugentobler, A. Jäggi, M. Meindl, L. Mervart, L. Prange, S. Schaer, T. Springer, C. Urschl, P. Walser, (2007). Bernese GPS Software Version 5.0, Edited by R. Dach, U. Hugentobler, P. Fridez, M. Meindl, Astronomical Institute, University of Bern, January 2007.

Carbone D., M. P. Poland, M. Diament and F. Greco (2017). The added value of time-variable microgravimetry to the understanding of how volcanoes work, Earth Sci. Rev., 169, 146-179, https://doi.org/10.1016/j.earscirev.2017.04.014

Colosimo G., M. Crespi, A. Mazzoni, M. Jones., D. Missiaen, F. Riguzzi (2012). Determination of the CNGS global geodesy. OPERA public note 132 v.3, https://www.earth-prints.org/handle/2122/7937

Crespi M., R. Falcone, F. Riguzzi, C. Scalzini (1999). Mixed terrestrial and GPS geodetic survey at the Laboratori Nazionali del Gran Sasso for the neutrino long baseline experiment. Bollettino di Geodesia e Scienze Affini, 2,1-15.

Crespi M., A. Mazzoni, G. Colosimo (2015). Global and local reference frames. Rendiconti Lincei, 26, 25-31, doi:10.1007/s12210-015-0435-0.

Crespi M. and L. Pinto (1991). Poligono di Lucera: compensazione della rete di inquadramento locale, Bollettino SIFET, N.2, 33-55.

D’Agostino G., S. Desogus, A. Germak, C. Origlia, D. Quagliotti (2007). L’accelerazione di gravità in Metrologia, Geofisica e Geodesia: utilizzo e riferibilità della misura. Proceedings of the V Meeting “Metrologia \& Qualità", MMG1, Turin 14-15 March, https://www.researchgate.net/publication/236609722

D’Agostino G., S. Desogus, A. Germak, C. Origlia, D. Quagliotti, G. Berrino, G. Corrado, V. d’Errico, G. Ricciardi, (2008). The new IMGC-02 transportable absolute gravimeter: measurements apparatus and applications in Geophysics and Volcanology. Ann. Geophys., 51, n.1, 39-49.

Devoti R., N. D’Agostino, E. Serpelloni, G. Pietrantonio, F. Riguzzi, A. Avallone, A. Cavaliere, D. Cheloni, G. Cecere, C. D’Ambrosio, L. Falco, G. Selvaggi, M. Métois, A. Esposito, V. Sepe, A. Galvani, and M. Anzidei (2017). The Mediterranean Crustal Motion Map compiled at INGV, Ann. Geophys., 60 (2), S0215, doi:10.4401/ag-7059.

Forlani G. (1990). Compensazione congiunta di osservazioni geodetiche e fotogrammetriche: il programma CALGE e la simulazione di un esempio realistico per cartografia a grande scala. Ricerche di Geodesia Topografia e Fotogrammetria 8, CLUP, Politecnico di Milano.

Greco F., G. Currenti, G. D’Agostino, A. Germak, R. Napoli., A. Pistorio, C. Del Negro (2012). Combining relative and absolute gravity measurements to enhance volcano monitoring at Mt Etna (Italy), Bull Volc., 74:1745-1756, doi:10.1007/s00445-012-0630-0.

Greco F., E. Biolcati, A. Pistorio, G. D’Agostino, A. Germak, C. Origlia, C. Del Negro (2015). Absolute gravity measurements at three sites characterized by different environmental conditions using two portable ballistic gravimeters, Eur. Phys. J. Plus, 130: 38, doi:10.1140/epjp/i2015-15038-0.

Jiang Z., V. Palinkas, F.E. Arias, J. Liard, S. Merlet, H. Wilmes, L. Vitushkin, L. Robertsson, L. Tisserand, F. Pereira Dos Santos, Q. Bodart, R. Falk, H. Baumann, S. Mizushima, J. Makinen, M. Bilker-Koivula, C. Lee, I.M.Choi, B. Karaboce, W. Ji, Q. Wu, D. Ruess, C. Ullrich, J. Kostelecky, D. Schmerge, M. Eckl, L. Timmen, N. Le Moigne, R. Bayer, T. Olszak, J. Agren, C. Del Negro, F. Greco, M. Diament, S. Deroussi, S. Bonvalot, J. Krynski, M. Sekowski, H. Hu , L.J. Wang, S. Svitlov, A. Germak, O. Francis, M. Becker, D. Inglis and I. Robinson (2012). The 8th International Comparison of Absolute Gravimeters 2009: the first Key Comparison (CCM.G-K1) in the field of absolute gravimetry. Metrologia, 49, 666-684, doi:10.1088/0026-1394/49/6/666.

Kazama T. and S. Okubo (2009). Hydrological modeling of groundwater disturbances to observed gravity: Theory and application to Asama Volcano, Central Japan. J. Geophys. Res. 114 (B08402), doi:10.1029/2009JB006391.

Kazama T., S. Okubo, T. Sugano, S. Matsumoto, W. Sun, Y. Tanaka and E. Koyama (2015). Absolute gravity change associated with magma mass movement in the conduit of Asama Volcano (Central Japan), revealed by physical modeling of hydrological gravity disturbances. J. Geophys. Res. 120 (2), 1263-1287, doi:10.1002/2014JB011563. Kreemer C., G. Blewitt, E. C. Klein (2014). A geodetic plate motion and Global Strain Rate Model. Geochem. Geophys. 


\section{Marco Fortunato et al.}

Geosyst., 15, 3849-3889, doi:10.1002/2014GC005407

Newell D. B., D. Van Westrum, O. Francis, J. Kanney, J. Liard, A. E. Ramirez, B. Lucero, B. Ellis, F. Greco, A. Pistorio, R. Reudink, D. Iacovone, F. Baccaro, J. Silliker, R. D. Wheeler, R. Falk, A. Ruelke (2017). Regional comparison of absolute gravimeters SIM.M.G-K1 key comparison. Metrologia, 54(1A), 07019 -Technical Supplement. DOI:10.1088/0026-1394/54/1A/07019

Niebauer T., G. Sasagawa, G. Faller, R. Hilt, F. Klopping (1995). A new generation of absolute gravimeters, Metrologia, 32, 159-18.

Pálinkáš V., O. Francis., M. Val'ko, J. Kostelecký , M. Van Camp, S. Castelein, M. Bilker-Koivula, J. Näränen , A. Lothhammer, R. Falk, M. Schilling, L. Timmen, D. Iacovone, F. Baccaro, A. Germak, E. Biolcati, C. Origlia, F. Greco, A. Pistorio, R. De Plaen, G. Klein, M. Seil, R. Radinovic, R. Reudink, P. Dykowski, M. Sẹkowski, D. Próchniewicz, R. Szpunar, M. Mojzeš, J. Jańk, J. Papčo, A. Engfeldt., P. A. Olsson, V. Smith, D. Van Westrum, B. Ellis, B. Lucero (2017). Regional comparison of absolute gravimeters, EURAMET.M.G-K2 key comparison. Metrologia, 54(1A), 07012-Technical Supplement, doi:10.1088/0026-1394/54/1A/07012.

Riguzzi F., H. Tan, C. Shen (2019). Surface volume and gravity changes due to significant earthquakes occurred in central Italy from 2009 to 2016, Int. J. Earth Sci., 108, 2047-2056.

Riguzzi F., C. Doglioni (2020). Gravity and crustal dynamics in Italy, Rend. Fis. Acc. Lincei. https://doi.org/10.1007/s12210-020-00881-2.

Riguzzi F., R. Devoti, G. Pietrantonio (2020). GNSS data provide unexpected insights in hydrogeologic processes, accepted for publication on Bollettino di Geofisica Teorica e Applicata.

Zerbini S., B. Richter, F. Rocca, T. van Dam, F. Matonti (2007). A combi- nation of space and terrestrial geodetic techniques to monitor land subsidence: case study, the southeastern Po plain, Italy, J. Geophys. Res., 112, B05401, https://doi.org/10.1029/2006/B004338 